\title{
Materials Research Society of India Established
}

Approximately 250 scientists and engineers attended the foundation meeting of the Materials Research Society of India (MRSI) at the Defence Metallurgical Research Laboratory in Hyderabad, India, on February 10, 1989. MRSI was established in recognition of today's critical role of materials science and engineering. The purpose of MRSI is to stimulate and accelerate growth of indigenous research and development of a wide range of materials and their applications. Its objectives are to promote interactions, advance the knowledge base through continuing education programs, disseminate information, and provide professional forums for discussing issues related to exploitation, conservation, development, etc.

The foundation day began with an inaugural session during which MRSI President C.N.R. Rao provided opening remarks. Prof. Rao is recognized as the moving spirit behind the formation of MRSI. The inaugural session was followed by technical sessions. The morning sessions were devoted to the aspects of science of materials, and afternoon sessions addressed aspects of materials processing. Morning lectures were delivered by T.V. Ramakrishnan (Condensed Matter Physics), C.N.R. Rao (Solid State Chemistry), M.S. Valiathan (Biomaterials), D. Chakravorty (Glasses), and K.J. Rao (Ceramics). Afternoon speakers included R.A. Mashelkar (Processing of Polymers and Composites), K.L. Chopra (Thin Film Fabrication), and Y.V.R.K. Prasad (Mechanical Processing of Metals). The technical program ended with an evening lecture entithed "Engineering Materials for Design" by V.S. Arunachalam. In addition to this program, a poster session offered original results of research by a number of materials scientists.

The foundation meeting ended with a business meeting of the members. Newly elected MRSI officers are:

President ................R. Rao

Vice Presidents. .....V.S. Arunachalam S. Ramaseshan E.C. Subba Rao S.K. Joshi K.L. Chopra Secretary-General ........P. Rama Rao

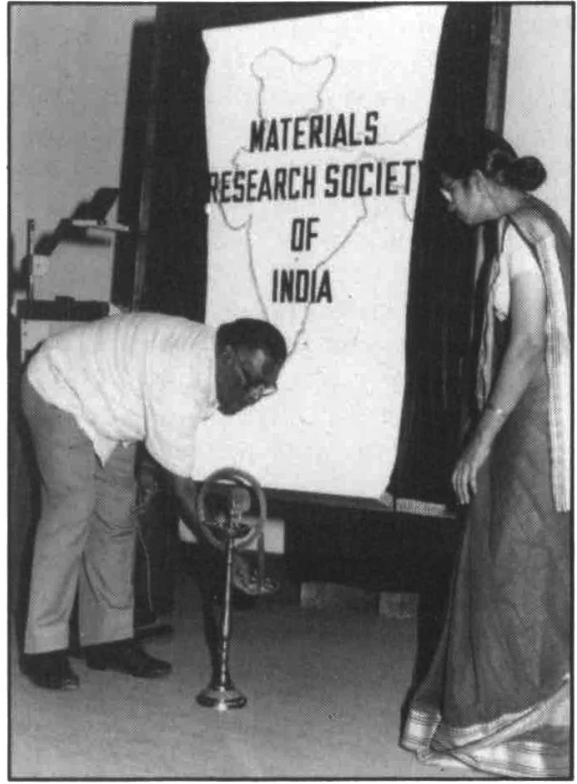

MRSI President C.N.R. Rao lights the lampat the foundation meeting of MRSI
Program Secretary . . . . R.A. Mashelkar Joint Secretary. . . . . . . A.S. Nigavekar Treasurer ............. S. Varadarajan In addition to electing Councillors of MRSI, eight different subject groups were formed in areas such as metals, polymers, ceramics, etc. Each group will consist of 20 active members who will pursue the growth of $R \& D$ in each of these specific areas. The journal, Bulletin of Materials Science, published by the Indian Academy of Sciences, will be the official journal of MRSI.

Launching of MRSI was heralded as a major event in the history of materials science in India by the attendees of the foundation meeting. A vigorous membership drive has started. Further information on the Society is available from:

Dr. P. Rama Rao

Secretary General, MRSI

Defence Metallurgical Research

Laboratory, Kanchan Bagh

P.O. DMRL

Hyderabad 500 258, India

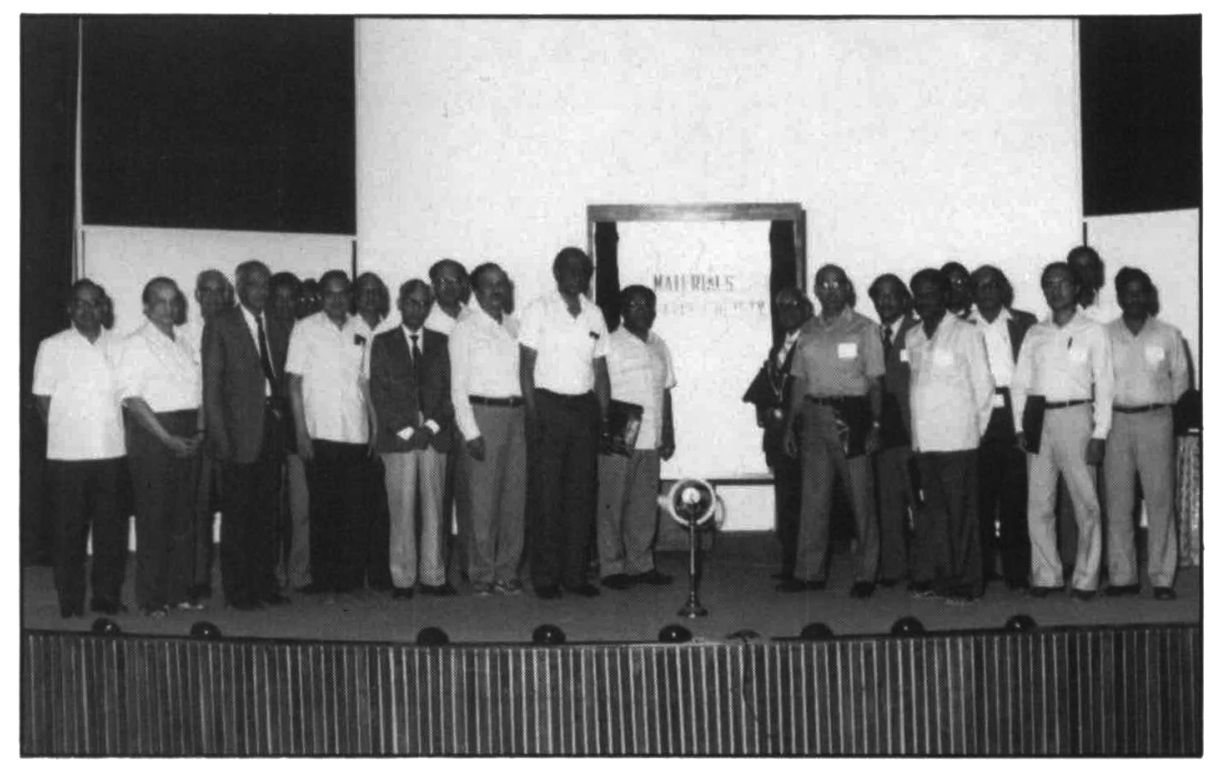

MRSI President C.N.R. Rao (center at left) and members of the Council of MRSI at foundation meeting. 